\title{
PENGARUH MODEL PEMBELAJARAN PROBLEM BASED LEARNING (PBL) TERHADAP MOTIVASI BELAJAR IPS TERPADU PADA MATERI KEGIATAN EKONOMI
}

\author{
Siti Nurjanah ${ }^{1}$, Risma Dwi Arisona ${ }^{2}$ \\ ${ }^{1}$ Institut Agama Islam Negeri Ponorogo \\ Nurjanahs740@gmail.com \\ ${ }^{2}$ Institut Agama Islam Negeri Ponorogo \\ arisona@iainponorogo.ac.id
}

\begin{abstract}
ABSTRAK
Penelitian ini merupakan suatu bentuk analisis terhadap model pembelajaran PBL yang diterapkan pada saat proses pembelajaran. Pemilihan model pembelajaran yang tepat sangatlah penting dilakukan, karena hal tersebut merupakan salah satu faktor yang mampu mempengaruhi motivasi belajar siswa. Seperti halnya proses pembelajaran di SMPN 2 Ponorogo yang menggunakan ceramah hasilnya masih kurang efektif, hal tersebut dilihat ketika pelaksanaan magang 2 sebelumnya. Penelitian ini berfokus untuk mengetahui pengaruh model pembelajaran Problem Based Learning terhadap motivasi belajar IPS Terpadu pada materi kegiatan ekonomi. Oleh karena itu peneliti menyusun pertanyaan yang akan dijawab, yaitu: Apakah terdapat pengaruh yang signifikan model pembelajaran Problem Based Learning terhadap motivasi belajar IPS Terpadu pada materi kegiatan ekonomi? Jenis penelitian yang diambil dalam penelitian ini adalah penelitian eksperimen, dimana penelitian ini dilakukan di SMP Negeri 2 Ponorogo, dengan jumlah sampel yang diambil sebesar 64 siswa. Metode penelitian survey dengan teknik pengumpulan data menggunakan angket dan dokumentasi. Hasil pengujian data yang dilakukan dengan menggunakan aplikasi SPSS Versi 25 memperoleh hasil $t_{\text {hitung }}$ sebesar 3,808 dan $t_{\text {tabel }}$ sebesar 1,997 ( $\left.t_{\text {hitung }}>t_{\text {tabel }}\right)$ atau jika dilihat dari sisi sig. 2 tailed $0,000<0,05$, yang artinya model pembelajaran Problem Based Learning (PBL) mempunyai pengaruh yang signifikan terhadap motivasi belajar IPS Terpadu pada materi kegiatan ekonomi.
\end{abstract}

Kata Kunci: Motivasi Belajar, Model Pembelajaran Problem Based Learning PBL

\section{ABSTRACT}

This research is a form of analysis of the PBL learning model that is applied during the learning process. Choosing the right learning model is very important, because this is one of the faktors that can affect student learning motivation. As with the learning process at SMPN 2 Ponorogo which uses lectures, the results are still ineffective, this can be seen during the implementation of the previous internship 2. This study focuses on determining the effect of the Problem Based Learning model on learning motivation for Integrated Social Studies on economic activity material. Therefore, the researchers compiled the questions to be answered, namely: Is there a significant effect of the Problem Based Learning learning model on the Integrated Social Studies learning motivation on economic activity material?The type of research taken in this study is experimental research, where this research was conducted at SMP Negeri 2 Ponorogo, with a total sample of 64 students. Survey research method with data collection techniques using questionnaires and documentation. The results of data testing performed using the SPSS version 25 application obtained the tcount of 3.808 and ttable 
JIIPSI: Jurnal Ilmiah Ilmu Pengetahuan Sosial Indonesia Nomor 1 Volume 1 Tahun 2021, hal 13-23

of 1.997 (tcount> ttable) or when viewed from the sig side. 2 tailed $0.000<0.05$, which means that the Problem Based Learning (PBL) learning model has a significant effect on the Integrated Social Studies learning motivation on economic activity material.

Keywords: Learning Motivation, PBL Problem Based Learning Model

\section{PENDAHULUAN}

Kelahiran PBL tidak lepas dari peran seorang guru sekolah dasar bernama Calestin Freniet pada tahun 1920. Saat ia mengembangkan sistem yang membuat siswa berperan aktif dalam proses pembelajaran dengan mengandalkan ketrampilan komunikasi, pembelajaran kooperatif, tanggung jawab individu dan evaluasi diri. ${ }^{1}$

Sejarah modern PBL kemudian dimulai pada tahun 1960an khususnya saat Kurikulum PBL pertama kali digunakan oleh McMaster Medical School in Hamilton Kanada pada tahun 1969. Pada tahun 1970 an di Mastricht University Medical School Eropa kurikulum PBL pertama kali kenalkan. Saat ini, PBL tersebar luas diberbagai bidang pendidikan tinggi selain ilmu kedokteran diantaranya bidang ekonomi dan hukum ${ }^{2}$

Problem Based Learning mempunyai prinsip tersendiri dimana menggunakan masalah yang riil sebagai sarana bagi peserta didik dalam mengembangkan pengetahuan sekaligus mengembangkan kemampuan berpikir serta kemampuan dalam memecahkan suatu permasalahan. ${ }^{3}$

Pembelajaran berdasarkan masalah ini mempunyai beberapa karakteristik sebagai berikut: a) Belajar dimulai dengan suatu masalah, b) Memastikan bahwa masalah yang diberikan berhubungan dengan dunia nyata peserta didik, c) Mengorganisasikn pelajaran dalam seputar permaslahan yang ada, bukan hanya diseputar disiplin ilmu, d) Memberikan tanggung jawab kepada pembelajar dalam membentuk, dan menjalankan proses belajar mereka e) Memakai kelompok dalam jumlah yang sedikit, f). Menuntut pembelajar agar mampu mengaplikasikan apa yang sudah dipelajari dalam bentuk produk maupun linerja. Dari hal ini diharapkan akan mampu memupuk skil peserta didik. ${ }^{4}$

${ }^{1}$ I Made Budi Arsika, dkk, Buku Pedoman Problem Based Learning (Denpasar: Universitas Udayana, 2016), 7.

${ }^{2} \mathrm{Ibid}, 8$.

${ }^{3}$ Muhammad Fathurrohman, Model-Model Pembelajaran Inovatif (Jogjakarta: Ar-Ruzz Media, 2017), 114.

${ }^{4}$ Ibid, 115 . 
Terdapat dua faktor yang mempengaruhi kegiatan pembeljaran yaitu faktor internal dan faktor eksternal.faktor intern factor faktor intern meliputi faktor yang berasal dari dalam diri seperti faktor jasmaniah, psikologis dan kelelahan. Salah satu faktor tersebut yaitu motivasi siswa itu sendiri. Sedangkan guru, model pembelajaran, media pembelajaran, dan lingkungan belajar merupakan pengaruh yang berasal dari eksternal. Dalam faktor ekternal ini guru merupakan salah satu hal yang sangat penting, karena dalam hal ini guru sangat berperan dalam menciptakan dan mengolah system pembelajaran yang menarik agar siswa dapat termotivasi sehingga pembelajaran berlangsung sesuai yang diharapkan. ${ }^{5}$ Untuk dapat belajar dengan baik diperlukan proses dan motivasi yang baik pula.

Motivasi memegang peranan yang sangat penting dalam proses pembelajaran. Motvasi belajar menjadi kekuatan atau daya pendorong yang kuat dalam diri peserta didik agar dapat belajar aktif, kreatif, inovatif, efektif dan menyenangkan dalam rangka untuk berusaha merubah perilaku baik dalam aspek kognitif, afektif maupun psikomotorik. ${ }^{6}$

Saat kegiatan belajar mengajar memilih strategi yang tepat merupakan hal yang sangat penting, karena dalam hal ini strategi merupakan rancangan dasar yang digunakan oleh seorang guru dalam melaksanakan proses pembelajarannya. Model pembelajaran Problem Based Learning merupakan salah satu cara yang dinilai efektif dalam menarik dan meningkatkan motivasi belajar siswa. ${ }^{7}$

Problem Based Learning ini merupakan model pembelajaran yang dalam prosesnya terpusat pada siswa. Dalam model pembelajaran ini siswa dilatih untuk berpikir secara kritis dalam mengembangakan ketrampilan pada saat memecahkan suatu permasalahan, dimana peserta didik dilatih dan diarahkan agar mampu menganalisis sendiri dalam memecahkan masalah yang ada, dimana dalam konteks pembelajaran ini menggunakan masalah yang nyata sebagai medianya. ${ }^{8}$

Melalui tahapan tersebut maka siswa akan terbiasa menghadapi permasalahan dan menemukan jalan penyelesaian masalah yang ada di sekitar mereka. Selain itu, dengan PBL ini akan terjadi pembelajaran yang bermakna

\footnotetext{
5 Iyar Windi Yanti, dkk, "Pengaruh Model Pembelajaran Problem Based Leaarning (PBL) Terhadap Motivasi Belajar Siswa,” No.01 (Juni, 2017), 03.

${ }^{6}$ Sindy Saras Shinta, "Pengaruh Variasi Gaya Mengajar Guru Terhadap Motivasi Belajar Siswa Pada Mata Pelajaran Pai Sma Negeri 1 Pekalongan Tahun Pelajaran 2017/2018,” (Juni 2018), 02.

${ }^{7}$ Rini Istanti, "Pengaruh Model Problem Based Learning ( $\left.P B L\right)$ Terhadap Motivasi Belajar Ipa Siswa Kelas V Sd Negeri Gadingan Kecamatan Wates," (Juli, 2015), 02.

${ }^{8} \mathrm{Ibid}, 03$.
} 
JIIPSI: Jurnal Ilmiah Ilmu Pengetahuan Sosial Indonesia Nomor 1 Volume 1 Tahun 2021, hal 13-23

karena siswa secara simultan akan mencari dan mengaplikasikan pengetahuannya dalam kehidupan sehari-hari.

Berdasarkan pemaparan diatas peneliti ingin meneliti apakah ada pengaruh positif model pembelajaran problem based learning terhadap motivasi belajar IPS Terpadu pada materi kegiatan ekonomi. Objek penelitian yang diambil adalah siswa kelas VII di SMP Negeri 2 Ponorogo. Berdasarkan hasil pengamatan yang dilakukan, peneliti pada saat magang dua mendapatkan temuan masalah yaitu sekitar $25 \%$ dari siswa masih terlihat pasif ketika proses pembelajaran berlangsung, mereka kurang bersemangat dalam mengikuti pelajaran, hal tersebut disebabkan proses pembelajaran yang kurang menarik sehingga siswa cenderung semaunya sendiri ketika pembelajaran.

Proses pembelajaran ini biasanya sering kali ditemukan ketika pembelajaran dilakukan menggunakan metode ceramah dimana dalam prosesnya guru menyampaikan materi yang kemudian dialanjutkan dengan memberikan tugas kepada siswa baik tugas secara individu maupun kelompok. Pada saat proses pembelajaran berlangsung aktivitas siswa dalam pembelajaran IPS belum tercapai secara maksimal, hal tersebut dapat dilihat ketika proses pembelajaran masih adanya beberapa siswa yang masih bergantung kepada temannya dalam kegiatan diskusi dan tugas yang diberikan, ada juga yang merasa canggung berbicara dengan temannya saat berdiskusi. Ada siswa yang aktif mengungkapkan pendapat dan ada juga yang pasif, selain itu masih banyak siswa yang tidak mau mencatat atau merangkum materi jika tidak ada himbauan dari guru, juga terdapat siswa yang izin keluar masuk kelas dengan alasan pergi ke toilet. Hal ini menunjukkan masih kurang efektifnya aktivitas siswa selama pembelajaran.”

Dengan adanya penelitian ini diharapkan mampu memberikan sumbangsih dalam dunia pendidikan, khususnya mengenai seberapa besar kedudukan model pembelajaran problem based learning dalam proses pembelajaran yang dapat mempengaruhi motivasi belajar siswa disekolah tersebut. Selain itu informasi yang diperoleh dalam penelitian ini mampu menambah informasi mengenai model pembelajaran problem based learning dan motivasi belajar siswa dalam mengikuti mata pelajaran IPS. Penelitian ini bisa digunakan sebagai bahan acuan untuk melakukan penelitian selanjutnya. 


\section{METODE PENELITIAN}

\section{Teknik Pengumpulan Data}

Teknik pengumpulan data yang digunakan dalam penelitian ini dengan instrumen penelitian berupa angket dan dokumentasi.

\section{Model Penelitian}

Penelitian ini menggunakan model penelitian asosiatif kausal yaitu penelitian yang bertujuan untuk mengetahui hubungan antara dua variabel atau lebih yang bersifat sebab akibat. Metode yang digunakan peneliti dalam melakukan penelitian yaitu metode penelitian survei yang artinya penelitian yang menggambarkan atau menguraikan sebuah keadaan sejelas mungkin dengan cara menggunakan kuesioner sebagai alat pengumpul data.

\section{Metode Analisis Data}

Analisis data dalam penelitian ini adalah statistika deskriptif. Variabel yang digunakan yaitu model pembelajaran Problem Based Learning sebagai variabel independen $(\mathrm{X})$ dan motivasi belajar IPS Terpadu pada materi kegiatan ekonomi sebagai variabel dependen (Y).

\section{HASIL PENELITIAN DAN PEMBAHASAN}

Berdasarkan data hasil penelitian dapat dilihat perbedaan tingkat motivasi belajar siswa antara kelas control dan kelas eksperimen. Untuk lebih jelasnya dapat dilihat pada tabel berikut ini:

Tabel 1.1 Perbedaan Tingkat Motivasi belajar siswa

\begin{tabular}{lllll}
\hline \multirow{2}{*}{ No } & Kelompok & \multicolumn{2}{l}{ Jumlah nilai } \\
\cline { 3 - 5 } & & Tinggi & Sedang & Rendah \\
\hline 1 & Control & 72 & $57-72$ & 57 \\
2 & Eksperimen & 81 & $61-81$ & 61 \\
\hline & & & \\
\hline
\end{tabular}

control dengan kelas eksperimen diatas dapat dijelaskan bahwa, tingkat motivasi belajar siswa pada kelas eksperimen lebih tinggi dibandingkan pada kelas control sehingga dapat dismpulkan bahawa model pembelajaran Problem Based Learning memiliki pengaruh yang positif terhadap motivasi belajar siswa.

\section{Uji Hipotesis}


JIIPSI: Jurnal Ilmiah Ilmu Pengetahuan Sosial Indonesia Nomor 1 Volume 1 Tahun 2021, hal 13-23

Uji hipotesis ini digunakan untuk menjawab tujuan penelitian yang dilakukan peneliti yaitu untuk mengetahui apakah ada pengaruh yang positif model pembelajaran Problem Based Learning terhadap motivasi belajar IPS Terpadu pada materi kegiatan ekonomi.

Hipotesis dalam penelitian ini $\mathrm{H}_{1}$ dipasangkan dengan hipotesis $\mathrm{H}_{0} . \mathrm{H}_{0}$ diuji dengan menggunakan independent T Test. Dimana jika nilai signifikansi 2 tailed $<$ dari 0,05 maka $\mathrm{H}_{0}$ ditolak dan $\mathrm{H}_{1}$ diterima, namun apabila nilai signifikansi 2 tailed $>0,05$ maka $\mathrm{H}_{0}$ diterima dan $\mathrm{H}_{1}$ ditolak sebagai hasil penelitian. Hipotesis yang diajukan pada penelitian ini adalah:

$\mathrm{H}_{\mathrm{o}} \quad$ : Model pembelajaran Problem Based Learning tidak mempunyai pengaruh yang signifikan terhadap motivasi belajar IPS Terpadu pada materi kegiatan ekonomi

$\mathrm{H}_{1} \quad$ : Model pembelajaran Problem Based Learning mempunyai pengaruh yang signifikan terhadap motivasi belajar IPS Terpadu pada materi kegiatan ekonomi

\section{Tabel 1.2 Hasil Uji t Independent Samples Test}

\begin{tabular}{|c|c|c|c|c|c|c|c|c|c|}
\hline & \multicolumn{2}{|c|}{$\begin{array}{l}\text { Levene's } \\
\text { Test for } \\
\text { Equality of } \\
\text { Variances }\end{array}$} & \multicolumn{7}{|c|}{ t-test for Equality of Means } \\
\hline & \multirow[b]{2}{*}{$\mathrm{F}$} & \multirow[b]{2}{*}{ Sig. } & \multirow[b]{2}{*}{$\mathrm{T}$} & \multirow[b]{2}{*}{ Df } & \multirow{2}{*}{$\begin{array}{l}\text { Sig. } \\
(2- \\
\text { tailed })\end{array}$} & \multirow{2}{*}{$\begin{array}{l}\text { Mean } \\
\text { Differen } \\
\text { ce }\end{array}$} & \multirow{2}{*}{$\begin{array}{l}\text { Std. } \\
\text { Error } \\
\text { Differen } \\
\text { ce }\end{array}$} & \multicolumn{2}{|c|}{$\begin{array}{c}95 \% \text { Confidence } \\
\text { Interval of the } \\
\text { Difference }\end{array}$} \\
\hline & & & & & & & & Lower & Upper \\
\hline $\begin{array}{ll}\text { has } & \text { Equal } \\
\text { il } & \text { variances } \\
\text { mot } & \text { assumed }\end{array}$ & $\begin{array}{r}3.62 \\
4\end{array}$ & .062 & $\begin{array}{r}3.80 \\
8\end{array}$ & 62 & .000 & 8.03125 & 2.10883 & 12.24674 & $\begin{array}{r}3.8157 \\
6\end{array}$ \\
\hline $\begin{array}{ll}\text { iva } & \text { Equal } \\
\text { si } & \text { variances } \\
& \text { not } \\
& \text { assumed }\end{array}$ & & & $\begin{array}{r}3.80 \\
8\end{array}$ & $\begin{array}{r}57.3 \\
78\end{array}$ & .000 & 8.03125 & 2.10883 & 12.25351 & $\begin{array}{r}3.8089 \\
9\end{array}$ \\
\hline
\end{tabular}

Dari data hasil analisis diatas menunjukkan bahwa nilai signifikansi 2 tailed mempunyai hasil 0,000. Berarti menunjukkan bahwa Ho ditolak dan $\mathrm{H}_{1}$ diterima atau bisa disimpulkan jika model pembelajaran Problem Based Learning 
mempunyai pengaruh yang signifikan terhadap motivasi belajar IPS Terpadu pada materi kegiatan ekonomi.

Problem Based Learning dapat membentuk siswa menjadi peserta didik yang memiliki sikap mandiri dalam belajar. Sikap mandiri disini dapat difahami bahwa ketika seorang siswa belajar, maka ia dapat memilih dan menentukan sendiri strategi yang dirasa sesuai dengan kemampuan atau gaya belajarnya. Dengan begitu siswa juga akan lebih terampil menggunakan strategi tersebut untuk belajar dan mammpu mengontrol proses belajaranya, serta termotivasi untuk dapat menyelesaikan permasalahan yang dijumpai dalam proses pembelajaran.

Dalam Problem Based Learning siswa memahami konsep suatu materi yang dipelajari dengan dihadapkan pada sebuah permasalahan, sehingga semua komponen motivasi belajar itu dapat dilakukan untuk mendukung berlangsungnya Problem Based Learning. Komponen motivasi yang dimaksud yaitu, kemampuan dalam membuktikan kebenaran saat melakukan diskusi, memperthankan pendapat, dan saat menyelesaikan tugas serta kemmpuan untuk memperoleh ilmu pengetahuan yang baru.

Peningkatan motivasi belajar dapat dipengaruhi oleh keefektifan dari penerapan model pembelajaran PBL, dimana dalam hal ini siswa benar-benar diajak untuk berfikir untuk memecahkan suatu permasalahan yang diberikan oleh guru, mereka diberikan kebebasan untuk memecahkannya, sehingga siswa menjadi lebih semangat untuk mengikuti pembelajaran. Permasalahan yang diberikan oleh guru kepada siswa merupakan permasalahan yang dekat dengan kehidupan sehari hari sehingga siswa lebih mudah untuk mencari solusi dari permasalahan tersebut.

Selama berdiskusi siswa yang kurang mampu tidak merasa malu untuk bertanya kepada anggota kelompoknya. Begitu pula siswa yang mampu menjadi semakin termotivasi untuk meningkatkan kemampuannya dengan banyak menyumbangkan pendapat terkait permasalahan yang ada. Bagi guru, adanya kolaborasi dengan kelompok menjadikan teman sebaya memiliki pengaruh penting pada perkembangan kognitif siswa. Oleh sebab itu, seharusnya belajar di kelas lebih baik melakukan kerja sama dengan teman yang lebih terampil atau 
JIIPSI: Jurnal Ilmiah Ilmu Pengetahuan Sosial Indonesia Nomor 1 Volume 1 Tahun 2021, hal 13-23

unggul agar dapat menyelesaikan tugas dengan baik. Hal ini sesuai dengan teori belajar Vygotsky. Kubiatko \& Vaculová (2011) dalam tesis Nurul Hasanah. ${ }^{9}$

Model Problem Based Learning memberikan kesempatan kesempatan kepada siswa untuk mendapatkan pengetahuan baru dari sumber referensi yang lain, baik melalui media cetak maupun internet yang digunakan untuk memperkuat bukti penyataan yang diperoleh dan difahami oleh siswa, yang kemudian disampaikan oleh peserta didik saat berdiskusi, serta untuk memecahkan permaslahan yang diberikan oleh guru. Penerapan model pembelajaran yang seperti ini akan memiliki peran lebih banyak untuk mendorong siswa lebih giat dan bersemanagat mengikuti proses pembelajaran dan membuat mereka merasa senang serta terpacu untuk senantiasa berantusias memberikan tanggapan terhadap materi pelajaran yang sedang dibahas, serta mengubah pandangan yang telah melekat dalam diri peserta didik bahawa mata pelajaran IPS bukanlah mata pelajaran yang banyak menuntut kemampuan untuk hafalan yang cenderung membosankan.

Ketika kegiatan berdiskusi kemampuan peserta diidk mulai terlihat, mereka mulai memunculkan ide dan gagasannya saat membahas persoalaan yang sedang didiskusikan maupun saat menanggapi kelompok komentar dari kelompok lain. Peserta didik mempunyai daya dorong yang lebih besar untuk dapat memberikan jawaban yang bersifat rasional. Karena dalam hal ini guru memberikan reward berupa penghargaan kepada pesrta didik yang aktif saat pembelajaran baik itu berupa tambahan nilai maupun hadiah lain serta memberikan dorongan bagi mereka yang masih kurang, agar mereka mau belajar lebih aktf seperti pesrta didik yang lain. Hal ini merupakan salah satu upaya guru untuk meningkatkan motivasi belajar siswa

Dalam penelitian Rini Istanti (2015) menunjukkan bahwa model pembelajaran PBL pada mata pelajaran IPA memiliki pengaruh yang positif terhadap motivasi belajar siswa kelas v SD Negeri Gadingan. ${ }^{10}$ Penelitian yang sebelumnya dengan penelitian yang baru sama-sama menggunakan 2 kelas dimana satu untuk kelas eksperimen yang digunakan untuk menerapkan model

\footnotetext{
${ }^{9}$ Nurul Hasanah, Pengaruh Model Projec Based Learning Terhadap Hasil Belajar Geografi SMA materi SDA Dengan Prinsip Ekoefisiensi, 58.

${ }^{10}$ Rini Istanti, "Pengaruh Model Problem Based Learning (PBL) Terhadap Motivasi Belajar Ipa Siswa Kelas V Sd Negeri Gadingan Kecamatan Wates., 05.
} 
pembelajran PBL dan kelas kontrol untuk model pembelajaran konvensional (ceramah), dimana dari kedua hal tersebut memilki hasil yang sama yaitu penerapan model pembelajaran PBL lebih efektif dibandingkan dengan model pembelajaran konvensional (ceramah).

Penelitian Rifka Annisaunnafi'ah yang berjudul pengaruh model Problem Based Learning Terhadap Motivasi Belajar IPS siswa kelas IV SD Negeri Grojogan Tamanan Banguntapan Bantul, yang menunjukkan bahwa juga terdapat pengaruh antara model pembelajaran PBL terhadap motivasi belajar siswa. ${ }^{11} \mathrm{Hal}$ ini sesuai dengan harapan dari proses pelaksanaan model pembelajarn PBL dimana siswa tidak hanya sekedar mendengarkan, mencatat kemudian menghfalkan materi yang diberikan oleh guru, akan tetapi dengan diterapkannya model pembelajran PBL membuat siswa lebih aktif dalam proses pembelajaran. ${ }^{12}$

Adanya pengaruh model pembelajaran PBL terhadap motivasi belajar siswa ini tidak terlepas dari karakteristik PBL yang menggunakan masalah untuk menstimulasi, mengontekstualkan dan mengintegrasikan pembelajaran. ${ }^{13}$ Permasalahan yang dikaji selama proses pembelajaran disesuaikan dengan materi yang dipelajari saat itu, dimana materi yang dikaji yaitu terkait kegiatan ekonomi. Dalam proses penyampaian materi ini lebih efektif menggunakan model pembelajaran PBL dibandingkan dengan model ceramah dan tanya jawab. Hal ini menyesuaikan dengan perkembangan siswa zaman sekarang khususnya siswa kelas VII di SMPN 2 Ponorogo, dimana mereka lebih menyukai kegiatan pembelajaran yang lebih banyak melibatkan peserta didik daripada gurunya, karena hal teresebut membuat siswa lebih bersemangat dalam mengikuti proses pembelajaran.
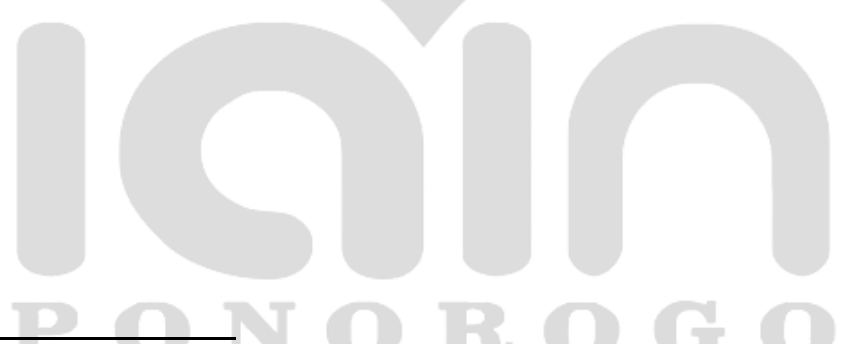

\footnotetext{
${ }^{11}$ Rifka Annisaunnafiah, "pengaruh model Problem Based Learning Terhadap Motivasi Belajar IPS siswa kelas IV SD Negeri Grojogan Tamanan Banguntapan Bantul”, (Juni 2015), 104.

12 Dewi, P.S.U., Sadia, W.I., Suma, K. 2014. Pengaruh Model Problem Based Learning terhadap Kemampuan Pemecahan Masalah Fisika melalui Pengendalian Bakat Numerik Siswa SMP. EJournal Program Pascasarjana Universitas Pendidikan Ganesha. Volume 4. (Online) (), diakses tanggal 7 Agustus 2020.

13 Newman, M.J. 2005. Problem Based Learning: An Introduction and Over view of the Key Features of the Approach. JVME, 32(1): hlm, 12-20, (Online) (http://www.utpjournals.com/jvme/tocs/321/12.pdf?origin=), diakses tanggal 7 Agustus 2020.
} 
JIIPSI: Jurnal Ilmiah Ilmu Pengetahuan Sosial Indonesia Nomor 1 Volume 1 Tahun 2021, hal 13-23

\section{PENUTUP}

Berdasarkan hasil penelitian yang diperoleh saat uji hipotesis yang mendapatkan perolehan nilai sig.2 tailed 0,000, dimana 0,000 tersebut $<0,05$. Sehingga dapat disimpulkan bahwa penerapan model pembelajaran Problem Based Learning memiliki pengaruh yang signifikan ( positif) terhadap motivasi belajar IPS Terpadu pada materi kegiatan ekonomi. Dimana dengan diterapkannya model pembelajaran ini membuat siswa lebih semangat dan giat dalam belajar karena model pembelajaran ini lebih terpusat kepada siswa yang membuat siswa lebih aktif dalam kegiatan belajar sehingga tidak membuat siswa cepat bosan ketika proses pembelajaran berlangsung.

\section{DAFTAR PUSTAKA}

Annisaunnafiah, Rifka. (2015). Pengaruh Model Problem Based Learning Terhadap Motivasi Belajar IPS siswa kelas IV SD Negeri Grojogan Tamanan Banguntapan Bantul, (06), 104.

Arsika, I Made Budi, dkk. (2016). Buku Pedoman Problem Based Learning. Denpasar: Universitas Udayana.

Dewi, P.S.U., Sadia, W.I., Suma, K. (2014). Pengaruh Model Problem Based Learning terhadap Kemampuan Pemecahan Masalah Fisika melalui Pengendalian Bakat Numerik Siswa SMP. E-Journal Program Pascasarjana Universitas Pendidikan Ganesha. Volume 4. (Online), diakses tanggal 7 Agustus 2020.

Fathurrohman, Muhammad. (2017). Model-Model Pembelajaran Inovatif. Jogjakarta: Ar-Ruzz Media.

Hasanah, Nurul. Pengaruh Model Projec Based Learning Terhadap Hasil Belajar Geografi SMA materi SDA Dengan Prinsip Ekoefisiensi

Istanti, Rini. (2015). Pengaruh Model Problem Based Learning (PBL) Terhadap Motivasi Belajar Ipa Siswa Kelas V Sd Negeri Gadingan Kecamatan Wates, (07), 02.

Newman, M.J. (2005). Problem Based Learning: An Introduction and Over view of the Key Features of the ApproachJVME, 32(1): hlm, 12-20, (Online) (http://www.utpjournals.com/jvme/tocs/321/12.pdf?origin=), diakses tanggal 7 Agustus 2020. 
Sinta, Sindy Saras. (2018). Pengaruh Variasi Gaya Mengajar Guru Terhadap Motivasi Belajar Siswa Pada Mata Pelajaran PAI SMA Negeri 1 Pekalongan Tahun Pelajaran 2017/2018, (06), 02.

Yanti, Iyar Windi, dkk. (2017). Pengaruh Model Pembelajaran Problem Based Leaarning (PBL) Terhadap Motivasi Belajar Siswa. 01, (06), 03.

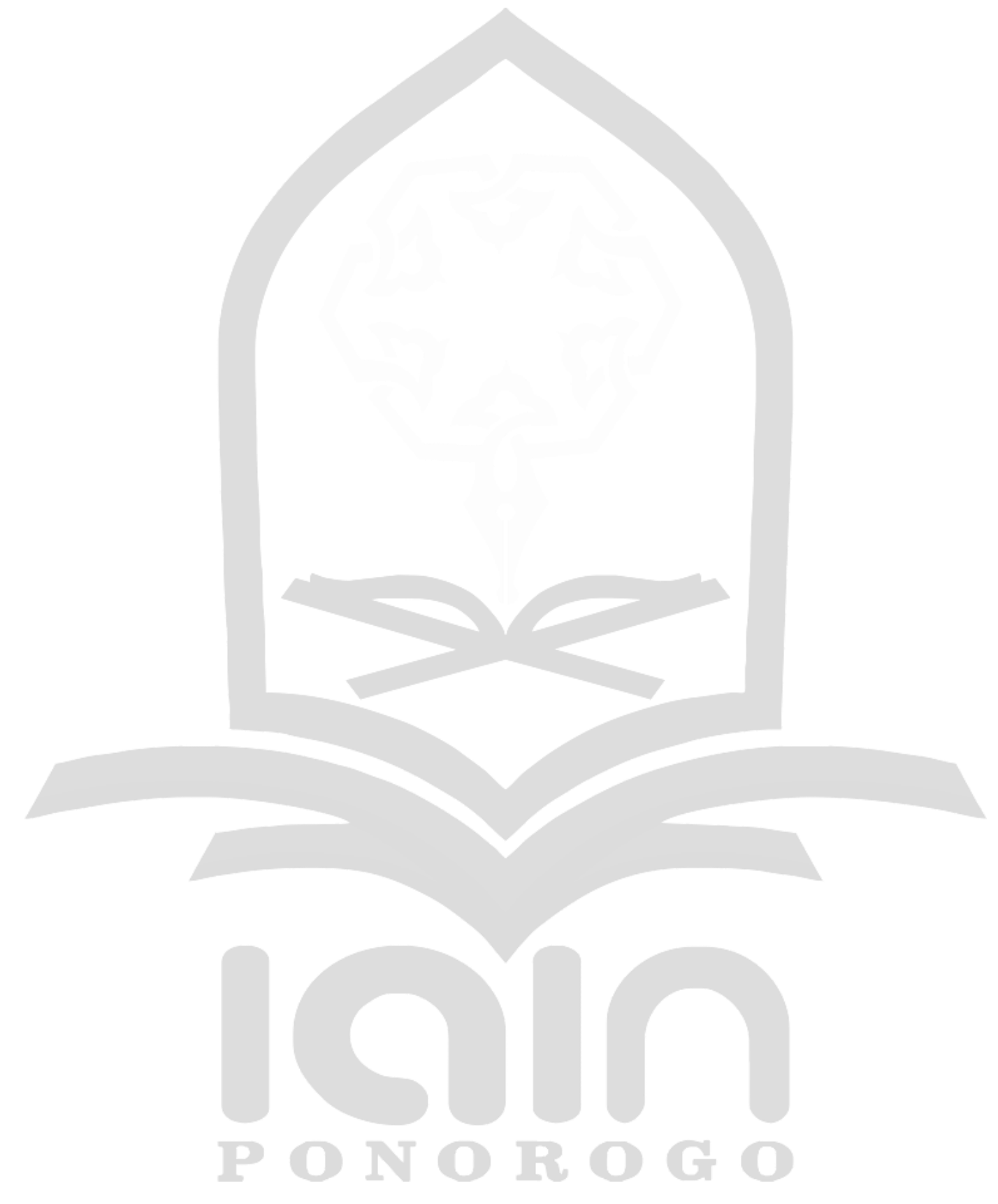

